\title{
13. PHYSICAL PROPERTIES EVALUATION
}

\author{
Richard H. Bennett and George H. Keller, National Oceanic and Atmospheric Administration, Atlantic \\ Oceanographic and Meteorological Laboratories, Marine Geology and Geophysics Laboratory, Miami, Florida.
}

\section{INTRODUCTION}

The field of soil mechanics has firmly established the importance of sediment mass physical properties as applied primarily to foundation design and problems of sediment bearing capacity and slope stability. In recent years marine geologists have employed a number of soil mechanics principles and tests to study the depositional processes and history of the ocean basins. These studies have dealt mainly with the regional distribution of the physical properties, their relationships to sediment acoustical properties, and the consolidation characteristics of deep-sea deposits (Hamilton, 1959; Richards, 1961, 1962; Keller and Bennett, 1968). Most of the sediment samples and related analyses to date have been restricted to the upper 10 meters of the sea floor due to the limited capability of coring devices. With the advent of the experimental Mohole program and later the Deep Sea Drilling Project (DSDP) came the first opportunity to study sediment physical properties to great depths below the sea floor. The DSDP samples have proved, and are still proving a unique opportunity to study the tectonics, lithology, biostratigraphy, and depositional history of the ocean basins, and particularly the processes of diagenesis which are directly related to changes in mass physical properties.

The measurement of water content, wet bulk density, porosity, relative strength, natural gamma radiation, and acoustical properties has been a standard shipboard practice in the DSDP. The importance of obtaining reliable mass properties data prompted a critical review of the testing procedures and analytical techniques used during DSDP Leg 16. This evaluation uncovered a number of problem areas and the purpose of this discussion is to review not only these areas so that researchers using the information are cognizant of its limitations, but also to offer suggestions for further improvement of physical properties data acquisition, systems, and techniques.

\section{CORE HANDLING AND DISTURBANCE}

Sediment cores are recovered in plastic liners within steel core barrels. After a core barrel is removed from the drill string it is cradled in a horizontal position to withdraw the plastic liner. The liner is removed from the core barrel after unscrewing two barrel sections, $20 \mathrm{~cm}$ and 27 $\mathrm{cm}$ in length, from the lower end of the barrel. The $20-\mathrm{cm}$ section extends below the liner and contains two core catchers and a plastic sock used to prevent the loss of extremely soft sediment. The sock interferes with the sediment in the catcher area and occasionally pieces of the plastic are torn loose and moved well up in the sediment core. Elimination of the plastic sock alleviates some of this disturbance; however, its use is best left to the discretion of the chief scientists.
A steel sleeve $7.6 \mathrm{~cm}$ in length is pressed into the lower end of the plastic liner to prevent damage and collapse of the plastic during coring. The steel sleeve and liner are retained in position by the two end sections of the core barrel. The sediment in the core catcher section and in the steel sleeve is usually the least disturbed material of the entire 9 meters of core. Generally, the lower portion of core Section 6 is considerably less disturbed than the other sections. The zero section and Section 1, however, contain sediment that has passed through the entire length of the barrel. This is a length of over 9 meters in the case of the zero section. The greater the distance from the lower end of the core barrel, the higher the degree of disturbance. Some sediment core sections are nothing more than slurries that can be poured easily from the liner.

After the plastic liner is withdrawn from the barrel, six 1.5-meter sections are cut and the zero section is removed (that which is in excess of $9 \mathrm{~m}$ ). The liner is cut first with a special knife blade and then the sediment is sheared and separated by hand. A recommended method would be to carefully slice the 1.5 -meter sediment core with a wire knife or sharp blade after the liner is cut. Shearing and tearing the sediment by hand with the ends of the liner sections disturbs the core section ends excessively and unnecessarily.

Quite often, large pockets of water occur between sediment core segments when sediment does not fill the plastic liner completely. In such cases, the common practice for draining the water is to punch holes in the liner by means of a hammer and a nail. After the water is removed, the separated core segments are pushed together by inserting a cloth-wrapped broom handle into the lower end of the liner. This procedure, of course, is carried out before cutting the 1.5-meter sections. Usually the core segments between the water pockets are not measured, and after they are pressed together at the upper end of the tube, the original segment lengths are unknown. Breaks in the sediment core can yield erroneous GRAPE data in these areas; this is discussed later. The procedure of pushing the sediment core segments together obviously increases sediment disturbance. The original breaks in the core may be undetectable by megascopic examination at the time of lithologic description and subsampling. In cases where liners are not completely filled, a recommended procedure would be to $\log$ in all core segments by length, noting areas of water pockets and breaks in their original spatial distribution when collected, and using a specially designed tool compatible with the inside diameter of the plastic liner to carefully place all core segments together.

Ends of selected sediment core sections are sampled for interstitial water chemistry after the liner is cut into 1.5meter lengths. The sediment is removed with a spatula or large syringe, leaving a sizable void at the end of the 
1.5 -meter section. These large voids result in core disturbance due to collapse, and the voids contribute to erroneous GRAPE data owing to the removal of sediment.

Core handling on the drilling floor during sectioning and later in the sediment laboratory was observed to be quite rough, with seemingly little concern about core disturbance. Treatment such as hammering holes in the plastic liner to remove water, pushing sediment together in the core liner to eliminate voids, bending the 9-meter core during removal from the core barrel and during its transport on deck all increase the likelihood of core disturbance. This can result in changes in sediment strength, composition, migration of water within the liner, and possible sediment flow. Although truly undisturbed sediment cores can not be obtained with the present coring techniques, sediment disturbance could be minimized substantially by careful core handling.

An extended core head was employed at DSDP 157A in an effort to obtain sediment cores with minimal disturbance. The extended core head passes through the hole in the bit and may extend to the bottom of the bit or further as desired. At Site 157A the core head extended $10 \mathrm{~cm}$ below the bit and recovery showed that one out of three cores was in somewhat better condition than when the extension was not used. The technique, however, did not prove as satisfactory as anticipated. Apparently more refinement of engineering design and testing is necessary before an optimum technique is achieved to recover sediment cores showing minimal disturbance.

The type and physical characteristics of the sediment, as well as drilling technique and sea state, are all important to the ultimate condition of the cores. Highly plastic sediment appears to reflect less disturbance than lowcohesion material of high water content. Well-indurated sediment of high strength sometimes shows undisturbed "biscuits" surrounded by an homogenized disturbed matrix. Varying degrees of disturbance are observed, from the undisturbed "biscuit" pieces of sediment to slurries. In general, shearing and flow features can be observed in various types of cored sediment. In the final analysis of the DSDP physical properties data, scrutiny and careful examination of sediment core photographs is strongly recommended

\section{DISCUSSION OF SYSTEMS AND TECHNIQUES}

\section{GRAPE}

Wet bulk density and porosity of the 1.5 -meter core sections are measured with the Gamma Ray Attenuation Porosity Evaluator (GRAPE), and data are recorded in the form of continuous analog graphs. GRAPE testing is made on a routine basis aboard the Glomar Challenger and discussions of the instrument and procedures are given by Peterson, Edgar, et al. (1970). Various aspects of this technique for measuring bulk density have been reported by Richards and Baumgartner (1967), Preiss (1968), Brier et al. (1969), and Bader, Gerard, et al. (1970). A recent study of wet bulk density determination by gamma-ray attenuation was made by Whitmarsh (1971), comparing the DSDP GRAPE data with bulk densities obtained by weighing 1.5 -meter core sections aboard the Glomar Challenger.
During Leg 16, numerous problems were encountered with the GRAPE and are reviewed in this discussion. In addition, data are presented from a detailed study comparing GRAPE results with shore-based laboratory wet bulk density and porosity values of carefully selected subsamples from Leg 16.

The calibration of the GRAPE is routinely checked using a water-filled plastic tube and an aluminum standard. The two to three minute scans were found to be inadequate in establishing a well-defined curve for each standard. In some instances, a straight-line trace was hardly discernable on the analog. Obviously, if the curves for the standards are not clearly established, the calibration is questionable, resulting in the use of inadequate scales to determine the actual GRAPE values. Furthermore, a poorly defined standard does little to indicate if the instrument is functioning normally prior to measurement of the cores.

Calibration of the GRAPE is usually made before testing each 9-meter core. In many cases, the scales obtained from the standards were considerably different for various tests. These calibration differences resulted in density variations of as much as $0.2 \mathrm{~g} / \mathrm{cc}$. In an effort to test for possible drift in the system, standards were run in a stationary position for over one hour but no drift was recorded. Further testing revealed that minor adjustment of the sensitivity of the GRAPE's analog recorder resulted in changes of the density and porosity scale by different magnitudes. Although the cause of the calibration changes was not firmly established, inadvertent movement of the sensitivity adjustment is suggested.

The calibration runs for the aluminum and water standards were checked in detail and found to show considerable variation ranging up to $0.11 \mathrm{~g} / \mathrm{cc}$ for density and as high as 7 percentage points for porosity. At present, the extreme variability in the GRAPE calibration curves appears to be totally unpredictable. This condition may be due to an inherent characteristic of gamma-ray emission and/or instrumentation. In any case, point values of sediment bulk density and porosity by GRAPE scanning are highly suspect. Average GRAPE values determined over a several-centimeter scan or the 1.5 -meter section scan appear to be more reliable and representative than point values.

The occasional occurrence of large pyrite nodules in the sediment tended to reduce porosity values considerably, in some cases to below zero. The presence of small nodules which may not be readily detected megascopically may result in erroneous values.

An effort was made to limit GRAPE measurements only to completely filled, undamaged sections. Warped and damaged core liners have a geometry between the source and sensor abnormal enough to produce error in the GRAPE readings. Section ends are highly suspect and commonly show erroneously high porosities and low bulk densities due to the removal of sediment for analyses of interstitial water chemistry. Breaks in the sediment cores which may not be detected prior to testing, and separations due to water pockets may result in excessively high GRAPE porosities and low bulk densities.

Considerable variation in the wall thickness of the plastic core liners was observed. The possible influence of 
these variations on bulk density and porosity measurements was not determined but is undoubtedly a contributing variable affecting GRAPE measurements.

\section{GRAPE Values Versus Shore-Based Laboratory Data}

Carefully selected subsamples were collected for shorebased laboratory determination of wet bulk density, porosity, water content, and average grain density from each DSDP site during Leg 16 . The methods for determining bulk density and porosity followed procedures described by Bennett and Lambert (1971) and are considered reliable and reproducible to better than $\pm 0.02 \mathrm{~g} / \mathrm{cc}$ and \pm 1 per cent for wet bulk density and porosity, respectively. GRAPE bulk density and porosity data were determined using the measured values of average grain density from laboratory tests. This gives more reliable GRAPE values than applying an assumed grain density to the calculations (Boyce, R.E. and Woodbury, P., personal communication). Direct comparison of the two techniques was made for wet bulk density and porosity using only the reliable GRAPE and laboratory measurements from the same intervals in the core sections. A relatively high degree of scatter is observed in sediments of higher density, although considerably more measurements were made in this material than in the lower density samples (Figure 1). Bader, Gerard, et al. (1970) pointed out that for wet bulk densities greater than $1.80 \mathrm{~g} / \mathrm{cc}$, the error in the GRAPE measurements becomes increasingly large, as high as 10 to 15 per cent for aluminum. The error should be minimized, however, by applying correct grain densities to the calculations, as were applied to the GRAPE data reported here.

These data (Figure 1) indicate clearly that 29 to 30 per cent of the bulk density comparisons differ by more than $0.05 \mathrm{~g} / \mathrm{cc}$, and only 36 per cent of the values agree within $0.02 \mathrm{~g} / \mathrm{cc}$. Comparison of GRAPE porosity versus laboratory porosity shows that 10 to 11 per cent of the values differ by greater than 5 per cent, and only 56 per cent of these data agree within 2 per cent (Figure 2). The scatter diagrams for wet bulk density and porosity, as well as the statistics, reveal a considerably larger disagreement than is desirable. Certainly, agreement to within 0.02 to 0.03 $\mathrm{g} / \mathrm{cc}$ for bulk density and 2 to 3 per cent for porosity is not an unreasonable demand for reliable data. These comparisons indicate random scatter which appears at the present time to be unpredictable.

\section{GRAPE Bulk Density Versus Bulk Density by Section Weight}

A routine shipboard procedure for measuring wet bulk density is carried out by weighing the 1.5 -meter core sections and assuming a constant volume based on core length and inside diameter of the plastic liner. Inherent in this procedure are a few easily recognized difficulties. First is the problem of weighing the 1.5-meter core with the ship in constant motion. The balance is a triple beam type and the method is rather gross. Secondly, any changes in the geometry of the plastic core liner, such as changes in the radius, increase the error in measurement of sediment volume (any error in the radius is squared). Finally, and of equal concern, is the fact that the core sections must be completely filled prior to weighing; this is not always the

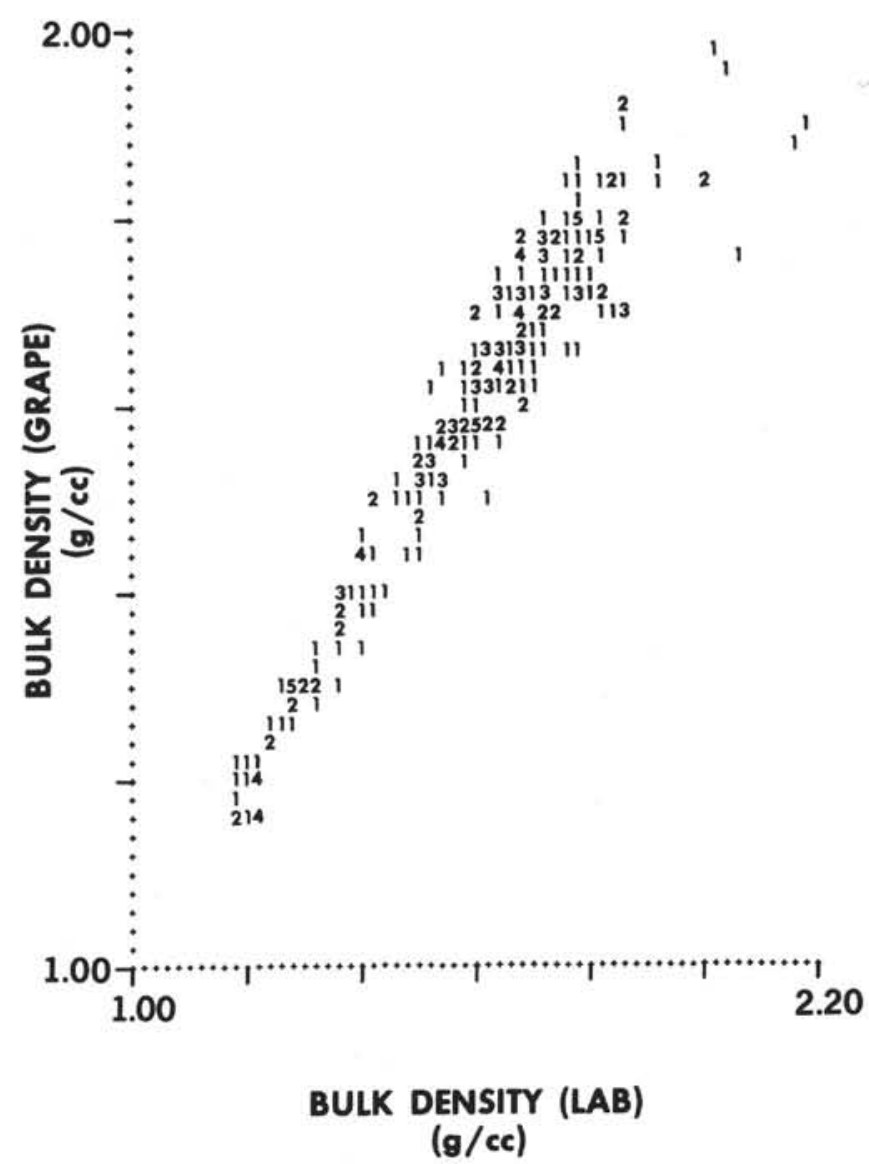

Figure 1. Comparison of GRAPE bulk density with that measured in the laboratory ashore.

case. The technique of weighing the sediment cores to determine wet bulk density, referred to here as bulk density by section weight, is considered only a rough approximation owing to these various problems. For the sake of comparison, however, GRAPE bulk density averages per core section versus bulk density by section weights are plotted in a scatter diagram (Figure 3). These data, as expected, show a relatively high degree of scatter and disagreement between the respective techniques. This scatter is due not only to the inherent limitations of the GRAPE, but also to the rather crude method in determining bulk density by section weighing. Scatter occurs in both high-density as well as low-density sediment, and these data indicate overall higher values as determined by the GRAPE than by the section weight method. This, of course, would be expected when either the core section volumes are less than the assumed values and/or the liners are not completely filled with sediment. An average GRAPE bulk density value determined by scanning the 1.5 -meter core sections would tend to average out erroneously high and low values and would be likely to be the more representative than the section weight value.

Subsampling of 15 to 20 grams of sediment from carefully selected portions of the cores complement the 


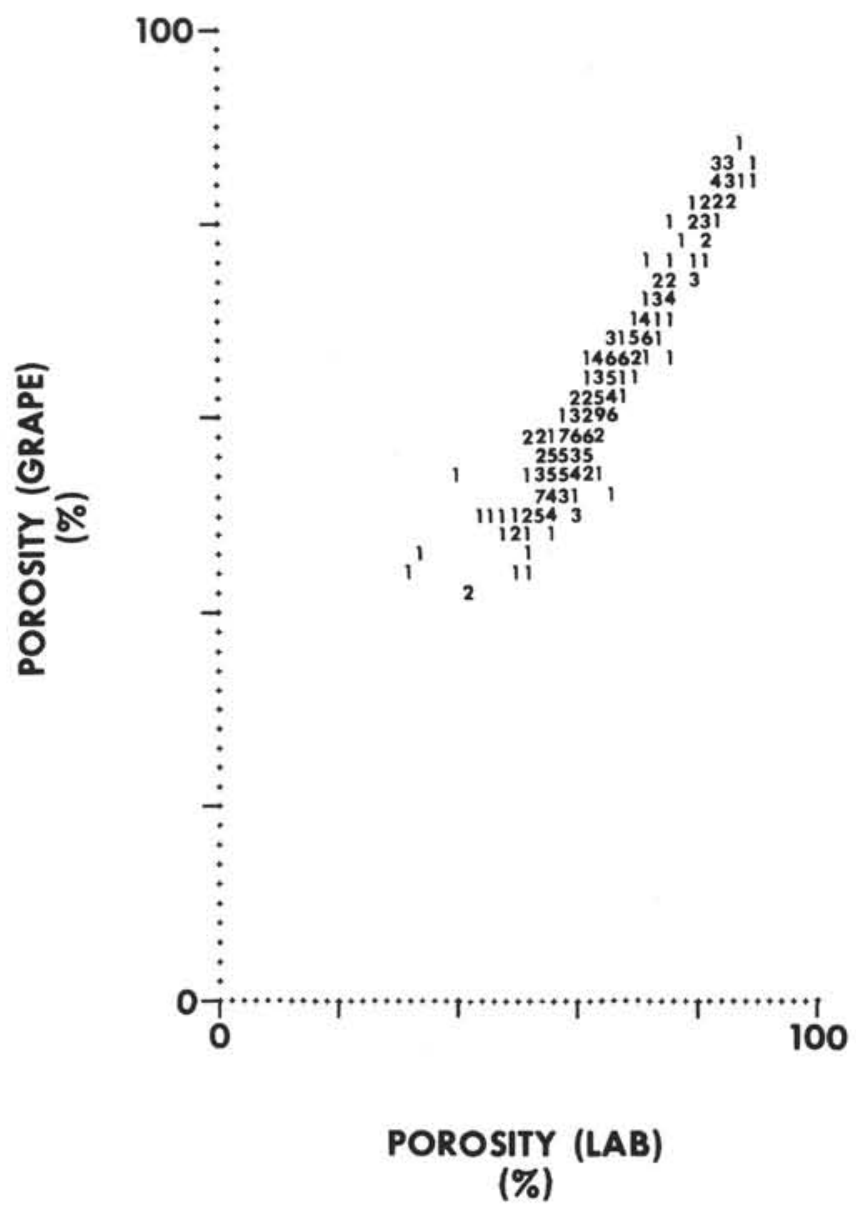

Figure 2. Comparison of GRAPE porosity with that measured in the laboratory ashore.

GRAPE data (average values per $1.5-\mathrm{m}$ section) and ensure that the most reliable sediment mass physical properties data are obtained. When lithologic boundaries occur in a given core section, GRAPE values may be averaged for each lithology.

\section{Syringe Technique}

Wet bulk density, porosity, and water content are determined by a routine shipboard technique using a very small ( 1 to $2 \mathrm{cc}$ ) syringe sample, withdrawn from the split core. The open end of the syringe is taped and the samples are stored in an open container in the laboratory, usually for several hours prior to analysis. The sample is examined for possible voids and separations before extruding a given amount of sediment from the syringe. The usual practice is to press the sample against a Kimwipe or a paper towel with the plunger to eliminate voids. This results in an unknown amount of moisture loss into the towel and an unknown change in sediment volume. After this treatment, approximately 0.5 to $1.0 \mathrm{cc}$ of sediment is extruded for weighing and then oven dried for determination of moisture content. The oven-dried samples remain in the laboratory out of the desiccator for periods of one-half to one hour prior to weighing. The effect of water absorption by the dry sediment is obvious.

Numerous syringes were checked for volume calibration and found to be in error by approximately $0.022 \mathrm{cc}$. This is a 4.4 per cent error in volume for a $0.5 \mathrm{cc}$ sample.

A comparison was made between shore-based laboratory and shipboard syringe wet bulk densities and porosities using corrected syringe volumes. These data show that 41 per cent of the bulk density comparisons did not agree closer than $\pm 0.05 \mathrm{~g} / \mathrm{cc}$. Most of the 41 per cent fell well outside this range. Only 13 per cent of the porosity values did not agree within \pm 5 per cent.

Water content is obtained from the syringe sample by weighing, oven drying, and reweighing to determine moisture loss. Oven temperatures were checked prior to shipboard laboratory analysis of Leg 16 samples and found to range from $106^{\circ} \mathrm{C}$ to $157^{\circ} \mathrm{C}$ for different areas in the oven. This was a result of two shelves being completely covered

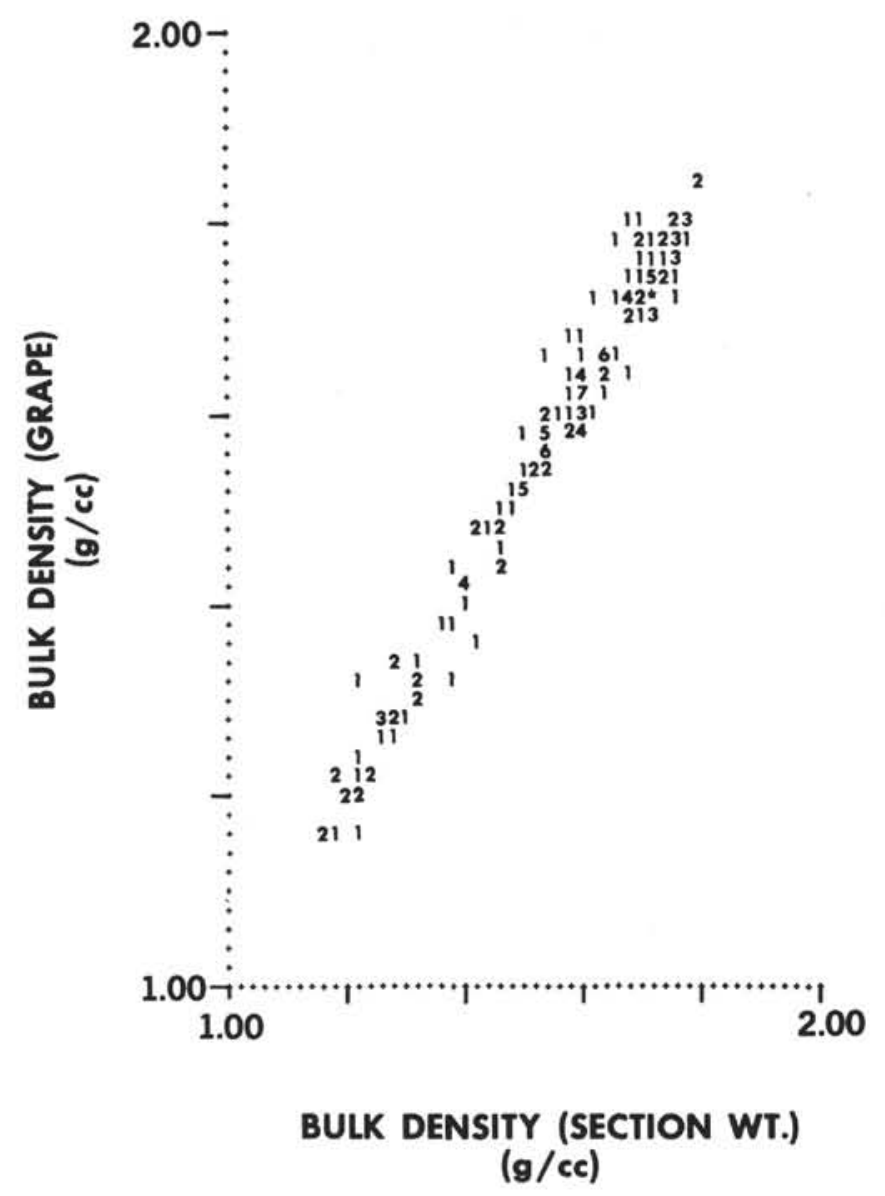

Figure 3. Comparison of GRAPE bulk density with that obtained by weighing of full core sections. 
with aluminum foil which drastically affected air circulation. Personal communication with shipboard technicians revealed that the foil had been placed in the oven several months prior to Leg 16 and perhaps as much as one year earlier. The foil was removed and the temperature conditions rechecked. An even temperature was then maintained throughout the oven for Leg 16 analysis (1967, ASTM standard for water content measurements, $110^{\circ} \mathrm{C}$ ). All water contents and porosities previously determined when the shelves were covered with foil are highly suspect. The combined difficulties in determining wet bulk density, porosity, and water content using the syringe technique include not only volume determination and weighing accuracy, but also water loss due to pressing the sediment on a towel, compaction of the sample, and the use of extremely small samples (500 to $800 \mathrm{mg}$ ). Shipboard weighing errors appear to be minimal, usually less than 1 per cent of the observed value for samples of 500 to 800 $\mathrm{mg}$ (checked during Leg 16). Tests with 20,10, 5, and 1 $\mathrm{mg}$ standards were found to have percentages of error of $0.5,2,4$, and 10 per cent, respectively. Obviously, the use of very small samples poses problems by magnifying any error that occurs during preparation of the sample and while testing.

Bulk densities and porosities were consistently low as compared with GRAPE measurements before volume corrections were applied to the syringe values. Bader, Gerard, et al. (1970) found that GRAPE porosities were generally 10 per cent higher than water-content-volume data. They also estimated weighing errors of approximately \pm 1 per cent and error in syringe volume of less than 5 per cent. This agrees well with the present study, indicating that problems with the syringe technique existed for quite some time. The entire technique is plagued with problems and should be abandoned. As a recommended procedure, the shipboard geologist should carefully select 10 to 20 gram subsamples in the least disturbed areas of the cores and place them in vials which can be sealed against moisture loss. The vials should be completely filled to prevent condensation and kept under refrigeration while aboard ship. Samples can be analyzed at a shore-based laboratory following standard techniques for measuring water content and average grain density (Lambe, 1951) and the techniques described by Bennett and Lambert (1971) for determining wet bulk density and porosity.

\section{Natural Gamma Radiation}

Natural gamma activity is measured on a routine basis aboard the Glomar Challenger. The 1.5-meter core sections are scanned in 7.6- $\mathrm{cm}$ intervals, each for a period of $75 \mathrm{sec}$, measuring total counts of activity. Shipboard handbooks indicate that the total volume of core scanned for 75-sec intervals is greater than the volume of the 7.6$\mathrm{cm}$ core segment. Apparently the actual volume of sediment scanned per interval never has been assessed. At present only a relative measure of activity is obtained from the raw data. If the volume of sediment scanned per unit time were known and wet bulk density, water content, and average grain density were obtained from other tests, the volume of the dry sediment scanned could be determined easily, resulting in more useful data. From these parameters a "radiation index" could be derived, relating the total number of gamma counts (activity) per unit time per unit volume of dry sediment. Natural gamma activity could be compared directly with depth throughout the lithologic sections and an assessment of the degree of correlation among different lithologies and their gamma activity characteristics would then be realized.

Due to the high degree of sediment disturbance in many cores, the natural gamma activity data is not necessarily representative of in situ conditions. However, if vertical mixing within a given lithology is limited, the values are probably fairly representative since the activity is not dependent upon the undisturbed physical properties of the sediment. Measurements are time-consuming, requiring approximately 25 minutes per 1.5 -meter core section, and testing should be limited to carefully selected, completely filled plastic liners. Separations in the sediment and incompletely filled liners such as the ends of certain sections show abnormally low activity values. Usually data from the middle portion of 1.5 -meter sections are the most reliable.

\section{Sonic Velocity}

Numerous sonic velocity measurements of selected sediment samples and of prepared samples of basalt were carried out during Leg 16 using the Hamilton Frame with the compatible electronic gear. The instrumentation and techniques are thoroughly discussed by Boyce (in preparation). The instrumentation is considered reliable; however, a number of problems were encountered which require attention in order to obtain useful data. Sonic velocities were measured on sediment samples removed from the core liners and also on sediment retained in the split core liners. Repeated measurements were made on the same sample whenever possible in order to obtain an approximation of the reproducibility of the method and an indication of operator technique. Velocities were remeasured on the same sample immediately following the initial test. Operator technique was found to be extremely erratic, and occasionally sonic velocities obtained by different technicians resulted in variations as great as 0.25 $\mathrm{km} / \mathrm{sec}$ on the same sample. Velocity variations obtained from reruns by the same operator resulted in differences as high as $0.19 \mathrm{~km} / \mathrm{sec}$. Of the 472 reruns, 72 per cent of the values showed a variation of $\pm 0.01 \mathrm{~km} / \mathrm{sec}$ or less. Although considerably higher variations were observed in 28 per cent of the cases, this method for determining sonic velocities appears to be generally reliable. Based on these data and tests made by Boyce (personal communication) measurements are reproducible to \pm 1 per cent, provided operator technique is consistent. These findings reveal a strong requirement for a consistent technique in order to minimize operator error.

Sonic measurements of sediment retained in split core liners are routinely corrected for travel time through the liner and for liner thickness, using values of $1.18 \mathrm{mi}-$ croseconds and $2.56 \mathrm{~mm}$ respectively. Several checks of liner thickness revealed considerable variation ranging from 0.47 to $3.91 \mathrm{~mm}$. Assuming the sonic velocity through plastic liners is constant, which implies uniform 
properties of the plastic from core to core, and then adjusting the travel time to correspond to the different liner thicknesses found, the sediment sonic velocities differ by as much as $30 \mathrm{~m} / \mathrm{sec}$ as compared to velocities determined using the routine corrections. A few measurements indicated that the sonic velocity through the liners may not be constant for different liners. Testing must include measurement of liner thickness and travel time through the liner in order to apply corrections to the data.

A further complication of in-liner velocity measurement is the unknown thickness and effect of the disturbed sediment in contact with the plastic liner. Most cored sediment exhibits this disturbed zone and the effect on the sonic velocity measurement is usually ignored. The most reliable sonic measurements are made on sediment that can be removed from the liners and placed directly in the Hamilton Frame. This direct method should be employed whenever possible.

Velocity tests should be made as rapidly as possible and the sediment sampled immediately following testing to minimize water loss due to evaporation. A few sonic tests were made on basaltic samples, and in one case a variation of $1.00 \mathrm{~km} / \mathrm{sec}$ was observed for the same sample. Other samples, however, revealed a considerably lower degree of variation between reruns. This high degree of variation is considered to be a result of operator technique. The reader is referred to a study by Christensen (this volume) of velocities in basaltic rocks from Leg 16. Leg 16 samples were tested after they had reached ambient temperature and no corrections were applied to the data for in situ temperature and pressure because most of the velocity measurements did not warrant such refinement.

\section{Sediment Shear Strength}

Prior to Leg 16, testing of sediment strength with an asphalt (AP-210) penetrometer was a routine procedure. The instrument was designed for use on asphalt and has not proven to be suitable for use on sediments. These tests have provided no quantitative strength data and only rough approximations of relative strength in a limited number of cases. Use of the asphalt penetrometer aboard the Glomar Challenger should be terminated.

Vane shear testing holds much more promise of providing strength data and the technique was first employed on Leg 16. Vane shear tests were made on sediment retained in the core catchers and steel sleeve by inserting a standard four-bladed vane $(2.54-\mathrm{cm}$ high $\times 1.27-\mathrm{cm}$ diameter $)$ parallel to the core axis. These core samples proved to be the least disturbed and usually the most amenable to vane testing. Testing is commonly made on both the "undisturbed" and remolded sediment which provides a measure of the sensitivity (ratio of undisturbed strength to remolded strength) of the sediment and an indication of possible core disturbance.

After vane testing in the catcher and/or sleeve sample, the sediment was extruded and split open for assessment of coring disturbance. Sediment samples were collected for later physical properties measurements at a shorebased laboratory. A detailed discussion of vane shear testing of submarine sediments is given by Richards (1961).

Valuable and reliable data can be obtained by making vane shear tests on high quality, relatively undisturbed
Glomar Challenger sediment samples, but only if tests are made on relatively undisturbed sediment. Close inspection for disturbance must be made before accepting the data as significant.

During Leg 16 the Swedish Fall Cone penetrometer was tested in carefully selected cores showing minimal disturbance. The fall cone must be calibrated with vane shear measurements in order to obtain reliable quantitative shear strength data. Calibration depends on sediment type and the degree of disturbance, which is a function of sampler design. The fall cone values obtained during Leg 16 , therefore, are most useful as a measure of relative strength because the instrument can not be accurately calibrated due to the variable degree of sediment disturbance. Other problems occasionally encountered were ship vibrations causing premature triggering of the instrument and artificial penetration of the fall cone. This required immediate readings to obviate the settling effect due to vibration. The reader is referred to a detailed study by Hansbo (1957) of the Swedish Fall Cone penetrometer.

\section{SUMMARY}

The DSDP Leg 16 evaluation of techniques and systems used in the shipboard determination of physical properties, as well as detailed shore-based analyses, has clearly revealed the urgent need for (a) high quality sediment cores; (b) the elimination of poor techniques and instruments; (c) the use of reliable methods and instruments; and (d) precise measurements by well-trained technicians who are cognizant of the basic care necessary to obtain reliable physical properties data. Instruments and techniques used aboard ship need to be checked by shipboard scientists and technicians on a regular basis. Frequent communication among geologists and technicians is of paramount importance, not only in maintaining high quality performance, but also in detecting instrument failures and related problems.

A high quality physical properties program demands that only carefully selected sediment cores showing minimal disturbance be used for testing and sampling rather than making routine measurements at some specified interval. For an effective study of mass physical properties, subsamples must be collected and carefully sealed in vials for shore-based analyses of wet bulk density, porosity, water content, and grain density. Average values from GRAPE scanning are more reliable than discrete point values. Determining bulk density by weighing core sections aboard ship contributes neither useful nor reliable data. The syringe technique for determining water content, wet bulk density, and porosity should be terminated. The technique is not reliable and is plagued with many problems.

Strength tests with the asphalt penetrometer have not provided useful data and should be discontinued and replaced with vane shear measurements performed in carefully selected cores. Vane measurements in the core catchers and steel sleeves usually provide the most reliable data owing to the lower degree of sediment disturbance commonly observed in these intervals as compared to most core sections. Vane shears of the undisturbed and remolded sediment are important for estimating sediment sensitivity and possible sampling disturbance. 
Sonic velocities measured by a single technician for an entire cruise are highly desirable in order to minimize variations due to operator technique. Tests made on samples removed from the core liners are more reliable than in-liner measurements. When in-liner tests are made, however, liner thickness and travel time through the liner must be determined. Reruns and frequent calibration are important to ensure the reliability of the velocity data.

Natural gamma activity measurements are considered reliable on a relative basis provided vertical mixing is limited. More useful data could be realized, however, if the total volume of sediment counted were known. A "radiation index" could relate the number of counts (activity) per unit time to the unit volume of dry sediment and direct comparisons could be made both vertically and horizontally.

\section{REFERENCES}

American Society for Testing and Materials, 1967. 1967 Book of A.S.T.M. Standards, Part II. Philadelphia (A.S.T.M.). 669.

Bader, R.G., Gerard, R.D. et al., 1970. Initial Reports of the Deep Sea Drilling Project, Volume IV. Washington (U.S. Government Printing Office). 753 p.

Bennett, R.H. and Lambert, D.N., 1971. Rapid and reliable technique for determining unit weight and porosity of deepsea sediments. Marine Geol. 11, 201.

Boyce, R.E. (in preparation). Initial Reports of the Deep Sea Drilling Project, Volume XV. Washington (U.S. Government Printing Office).
Brier, C., Bennin, R. and Rona, P.A., 1969. Preliminary evaluation of a core scintillation counter for bulk density measurement in marine sediment cores. J. Sediment. Petrol. 39, 1509.

Hamilton, E.L., 1959. Thickness and consolidation of deep-sea sediment. Bull. Geol. Soc. Am. 70, 1399.

Hansbo, S., 1957. A new approach to the determination of the shear strength of clay by the fall-cone test. Proc. Roy. Swedish Geotech. Inst. 8, 1.

Keller, G.H. and Bennett, R.H., 1968. Mass physical properties of submarine sediments in the Atlantic and Pacific Basins. Proc. Intern. Geol. Congr., 23rd, 8, 33.

Lambe, T.W., 1951. Soil Testing for Engineers. New York (John Wiley \& Sons, Inc.), 165.

Peterson, M.N.A., Edgar, N.T. et al., 1970. Initial Reports of the Deep Sea Drilling Project, Volume II. Washington (U.S. Government Printing Office).

Preiss, K., 1968. Non-destructive laboratory measurement of marine sediment density in a core barrel using gamma radiation. Deep-Sea Res. 15, 401.

Richards, A.F., 1961. Investigations of deep-sea sediment cores, I. Shear strength, bearing capacity and consolidation. U.S. Navy Hydrographic Office, Tech. Rept. 63.

Richards, A.F., 1962. Investigations of deep-sea sediment cores, II. Mass physical properties. U.S. Navy Hydrographic Office, Tech. Rept. 106.

Richards, A.F. and Baumgartner, T., 1967. Continuous nondestructive measurement of bulk density by gamma ray transmission through sediment inside core barrels (abstract). Proc. 7 th Intern. Sediment. Cong.

Whitmarsh, R.B., 1971. Precise sediment density determination by gamma-ray attenuation alone. J. Sediment. Petrol. 41, 882 . 